\title{
Aspectos fenotípicos, genotípicos e de diagnóstico da bactéria A. pleuropneumoniae
}

Phenotypic, genotypic and diagnostic aspects of the bacterium A. pleuropneumoniae

\author{
Mateus Matiuzzi da Costa ${ }^{1}$ Cátia Silene Klein ${ }^{2}$ Roberta Mattos Collares ${ }^{3}$ \\ Clarissa Silveira Luiz Vaz ${ }^{1}$ Raquel Balestrim ${ }^{4}$ Augusto Schrank ${ }^{5}$ \\ Sergio Ceroni da Silva ${ }^{6}$ Itamar Antônio Piffer $^{7}$ Irene Silveira Shrank ${ }^{5}$
}

\section{- REVISÃO BIBLIOGRÁFICA -}

\section{RESUMO}

A pleuropneumonia suína (PPS) provoca prejuízos significativos na suinocultura no mundo. $O$ agente etiológico é a bactéria Actinobacillus pleuropneumoniae (App), que apresenta 15 sorotipos descritos, os quais variam consideravelmente em relação a sua patogenicidade. Nesse sentido, a precisa caracterização patotípica desta bactéria é de grande importância para a adoção de medidas de controle e profilaxia. O diagnóstico e a sorotipificação deste patógeno são realizados pelas técnicas microbiológicas convencionais. Entretanto, problemas nestes esquemas podem ser observados, especialmente em isolados de rebanhos sem histórico de PPS. No Brasil, diversos esforços vêm sendo aplicados no sentido de desenvolver técnicas moleculares que auxiliem no diagnóstico da infecção crônica ocasionada por este agente, principalmente em rebanhos presumidamente sadios e com infecção subclínica. Nesta revisão, são discutidos os resultados obtidos na caracterização de isolados de A. pleuropneumoniae e espécies relacionadas provenientes tanto de suínos com PPS, como de animais presumidamente isentos da infecção. Apresentamos, ainda, perspectivas para o desenvolvimento de metodologias que possibilitem o diagnóstico precoce e a melhor compreensão dos mecanismos de virulência deste patógeno.

Palavras-chave: $A$. pleuropneumoniae, diagnóstico, $P C R, r D N A$ $16 S, R A P D$.

\section{ABSTRACT}

Swine pleuropneumonia is responsible for severe losses in swine breeding farms around the world. The aethiological agent, A. pleuropneumoniae, is classified according to different degrees of pathogenicity in 15 serotypes. The correct identification and serological classification of this bacterium is very important for the adoption of control measures. The diagnosis of swine pleuropneumonia is performed by conventional microbiological techniques, however problems in A. pleuropneumoniae identification have been reported. In Brazil, some studies applying molecular tests have been developed specially in isolates from swine herds with subclinical and chronic infections. In this review, we discuss the results on molecular characterization of $\boldsymbol{A}$. pleuropneumoniae and related species from herds with or without pleuropneumonia. Moreover, we also discuss the perspectives to development early diagnostic methods and to improve understand of pathogenesis mechanisms of these bacteria.

Key words: A. pleuropneumoniae, diagnostic, PCR, rDNA $16 S$ RAPD.

\section{INTRODUÇÃO}

A pleuropneumonia suína e a bactéria Actinobacillus pleuropneumoniae (App)

A estrutura da produção de suínos nos países industrializados tem se modificado muito nos últimos anos. $\mathrm{O}$ aumento das populações confinadas, associado a fatores de manejo e ambientais, como temperatura, umidade e presença de amônia, bem

\footnotetext{
'Medico Veterinário, MSc., Professor, Universidade do oeste de Santa Catarina, Xanxerê, SC, Pontifícia Universidade Católica do Paraná, Av. da Univ., n. 500, Jardim Coopagro, 85902-532, Toledo, PR, Doutorando Universidade Federal do Rio Grande do Sul. Av. Bento Gonçalves, 9500. Prédio 43421, 91501-970, Porto Alegre, RS, Brasil.

${ }^{2}$ Biólogo, MSc, Empresa Brasileira de Pesquisa Agropecuária (EMBRAPA) Suínos e Aves, Caixa postal 21, 89700-000, Concórdia, SC. ${ }^{3}$ Médico veterinário, Doutorando, Universidade Federal de Pelotas (UFPel).

${ }^{4}$ Acadêmico de biologia, bolsista do Programa Institucional de Bolsas de Iniciação Científica (PIBIC), Conselho Nacional de Desenvolvimento Científico e Tecnológico (CNPq).

${ }^{5}$ Farmacêutico, PhD, Professor, Centro de Biotecnologia, Universidade Federal do Rio Grande do Sul (UFRGS), Av. Bento Gonçalves, 9500, Prédio 43421, 91501-970, Porto Alegre, RS, Brasil. E mail: irene@ dna.cbiot.ufrgs.br.

${ }^{6}$ Médico Veterinário, PhD, Professor Faculdade de Veterinária, UFRGS, Av. Bento Gonçalves, 9090, 91540-000, Porto Alegre, RS, Brasil. ${ }^{7}$ Biólogo, PhD, EMBRAPA Suínos e Aves.
} 
como fatores inerentes ao animal, como estresse e grau de imunidade, contribuíram para o aparecimento de enfermidades respiratórias (CHRISTENSEN et al., 1999). Conforme SOBESTIANSKY et al. (1987), a rinite atrófica e as pneumonias causam prejuízos significativos à suinocultura, devido a sua cronicidade nos rebanhos e à falta de esclarecimento dos produtores com relação às medidas de controle a serem utilizadas. Estima-se que as pneumonias sejam responsáveis pela perda de 2,4 suínos com peso de $95 \mathrm{~kg}$ para cada 100 animais abatidos no Brasil (PIFFER \& BRITTO, 1993).

A pleuropneumonia suína (PPS) é uma das doenças bacterianas mais importantes do trato respiratório, ocorrendo na maioria dos países suinocultores, onde ocasiona prejuízos aos sistemas de produção (HAESEBROUCK et al., 1997; PIFFER et al., 1997). A importância da PPS decorre do fato de a enfermidade poder apresentar tanto manifestações clínicas severas, como se tornar crônica e subclínica na maioria dos rebanhos, causando perdas econômicas, devido à morte dos animais enfermos, à redução na produtividade e ao aumento nos custos com medicação e vacinação (TAYLOR, 1999). No Brasil, a PPS foi diagnosticada pela primeira vez em 1981 (LOCATELLI et al., 1981). A partir daí, vários surtos foram observados no Sul do país (PIFFER et al., 1987). A principal rota de disseminação da enfermidade é a aerógena. As bactérias são transmitidas principalmente pelo contato direto entre os animais durante os surtos e pela introdução de portadores em populações sem histórico prévio da infecção (TAYLOR, 1999). Trabalhos recentes comprovaram o papel importante dos aerossóis e do movimento do ar na disseminação de A. pleuropneumoniae em distâncias superiores a 2,5 metros (JOBERT et al., 2000; SAVOYE et al., 2000; CHIERS et al., 2002).

A PPS é caracterizada por pneumonia necrótica hemorrágica e pleurite fibrinosa (HAESEBROUCK et al., 1997). Os sinais clínicos variam de acordo com a idade dos animais, o nível de imunidade, condições ambientais e o grau de exposição ao agente infeccioso. Na forma superaguda da doença, ocorrem febre, apatia, diarréia e vômito e, em alguns casos, podem ocorrer falências circulatória e cardíaca. Com o desenvolvimento da enfermidade, o animal pode tornar-se cianótico, e na fase terminal, é observada dispnéia intensa, podendo ocorrer a morte de 24 a 36 horas após o aparecimento dos sinais clínicos. Na forma aguda, são observadas elevação discreta da temperatura e o avermelhamento da pele, bem como a recusa da ingestão de água e alimento e a relutância ao exercício (TAYLOR, 1999). Sinais clínicos respiratórios severos, como dispnéia e tosse, são evidentes. A forma subaguda e a crônica desenvolvem-se logo após o desaparecimento dos sinais agudos, sendo observada pouca ou nenhuma febre e eventualmente a ocorrência de tosse intermitente e com intensidade variável. $\mathrm{O}$ apetite pode estar reduzido, o que pode contribuir para a diminuição do ganho de peso, sendo que os animais enfermos são identificados pela sua relutância ao movimento (TAYLOR, 1999). Esta doença vem sendo associada com até $20 \%$ de redução no desenvolvimento corpóreo (ROHRBACH et al., 1993). Segundo STRAW et al. (1989), a pleuropneumonia ocasiona, em média, uma diminuição no ganho de peso diário de $34 \%$ e uma redução de $26 \%$ na eficiência alimentar. Além disso, em torno de 10 a $20 \%$ das carcaças dos animais provenientes de rebanhos infectados são totalmente condenadas no frigorífico. A mortalidade pode ser de 10 a $20 \%$ durante os surtos, porém, é usualmente menor que $1 \%$ em rebanhos com infecção crônica (CHRISTENSEN et al., 1999).

O A.pleuropneumoniae (App) é o agente etiológico da pleuropneumonia suína. Esta bactéria é gram-negativa, encapsulada e com morfologia de cocobacilo. Com base na exigência de NAD (Nicotinamida Adenina Dinucleotídeo) para a sua multiplicação, esta espécie pode ser divida em dois grupos: o biótipo 1, NAD-dependente e o biótipo 2, que não necessita do NAD para seu desenvolvimento (FODOR et al., 1989; DOM et al., 1994). Tanto em estudos de campo, como em infecções experimentais, o biótipo 2 se mostrou menos virulento que o biótipo 1 (DOM \& HAESEBROUCK, 1992). Vários fatores são associados à virulência de App entre eles a cápsula, os lipopolissacarídeos de cadeia longa, as proteínas externas de membrana, as proteínas de ligação a transferrina, as proteases, as toxinas Apx, e as adesinas (FREY et al., 1994; HAESEBROUCK et al., 1997).

O polissacarídeo capsular tem sido grandemente associado à patogenicidade. Estudos envolvendo mutações têm comprovado a significativa redução na virulência de isolados acapsulados, que podem ser utilizados para o preparo de vacinas vivas (INZANA et al., 1993; RIOUX et al., 2000). As toxinas Apx produzidas por estas bactérias pertencem a uma família de proteínas geneticamente relacionadas, as quais são denominadas RTX (Repeat Toxins), sendo também produzidas por uma variedade de bactérias gram-negativas (TASCÓN et al., 1994). Segundo FREY (1995), dados epidemiológicos indicam que as exotoxinas produzidas por App estão associadas com a patogenicidade da bactéria para os suínos. Existem muitas indicações relacionando a função das toxinas 
na evasão do sistema de defesa do hospedeiro, pela morte de macrófagos e neutrófilos. Além disto, a produção excessiva de radicais livres de oxigênio pode danificar os tecidos adjacentes e promover grande lesão tecidual (JANSEN et al., 1995).

O App produz diferentes RTX (Apx), que apresentam efeitos citotóxicos e hemolíticos distintos (FREY, 1995; SCHALLER et al., 1999). Todos os sorotipos de App variam quanto à secreção de uma ou duas das toxinas ApxI, II e III (JANSEN et al., 1993). O sinergismo na produção de hemólise observado entre as toxinas Apx e as toxinas de Staphylococcus aureus é denominado de efeito CAMP (Christie-AktinsMunch-Peterson), o qual é normalmente utilizado no diagnóstico bacteriológico (FREY et al., 1994).

As toxinas ApxI e ApxII foram encontradas em espécies consideradas menos virulentas, incluindo o Actinobacillus suis, onde foram denominadas de ApxIA $_{\text {var suis }}$ e ApxIIA var suis $(B U R R O W S$ \& LO, 1992; OSTAAIJEN et al., 1997). DOM et al. (1994) demonstraram a presença de uma proteína, que reage com anticorpos para toxina ApxII, nos isolados de App pertencentes ao biótipo 2. Recentemente, um quarto tipo de toxina RTX foi descoberta, sendo denominada Apx IV. Esta toxina é expressa somente in vivo estando presente em todos os isolados de App, o que demonstra seu grande potencial para o diagnóstico da PPS e caracterização deste patógeno (SCHALLER et al., 1999; SCHALLER et al., 2001, CHO \& CHAE, 2001). As toxinas Apx induzem uma forte reação imunológica em suínos infectados e são usadas como antígenos em vacinas de subunidades, com o intuito de induzir imunidade protetora (SCHALLER et al., 2000).

A sorotipificação é uma das ferramentas mais importantes em estudos epidemiológicos e programas de controle. É baseada nas diferenças sorológicas de polissacarídeos capsulares, permitindo a discriminação destas bactérias em quatorze sorotipos distintos (BECK et al., 1994; FREY, 1995). Destes, doze foram classificados no biótipo 1, enquanto que outros dois no biótipo 2 (DOM et al., 1994). Recentemente, o sorotipo 15 de App foi proposto para isolados australianos, que se distinguem consideravelmente dos demais (BLACKALL et al., 2002). Observações a campo indicaram que os sorotipos 1, 5, 9, 10 e 11 são os mais virulentos, estando geralmente envolvidos em surtos severos, com extensas lesões pulmonares e elevada mortalidade (HAESEBROUCK et al., 1997). Os outros sorotipos, em especial o sorotipo 3, possuem menor virulência, mas também são encontrados ocasionando enfermidade em diversos países (BECK et al., 1994). No Brasil, os sorotipos 3, 5 e 7 são considerados de grande ocorrência e importância, principalmente, para os criatórios suínos na região Sul (PIFFER et al., 1987; 1997).

\section{Diagnóstico e sorotipificação de App}

O diagnóstico presuntivo da pleuropneumonia pode ser realizado através dos achados de necropsia, como pleurisia, pneumonia exsudativa e necrose. Entretanto, o diagnóstico definitivo exige o isolamento do agente e sorotipificação, bem como a diferenciação de outros patógenos presentes no trato respiratório, como: Mycoplasma hyopneumoniae, Haemophilus parasuis, Pasteurella multocida e Bordetella bronchiseptica (GRAM et al., 1996). As técnicas tradicionais para o diagnóstico da infecção por App envolvem a cultura bacteriana e testes imunológicos, como ELISA e fixação do complemento (SCHALLER et al., 2001).

O App é normalmente isolado dos tecidos e secreções em meio de ágar sangue suplementado com $5 \%$ de sangue ovino, utilizando uma semeadura perpendicular de Staphylococcus aureus, que supre o NAD necessário para o desenvolvimento do biótipo 1. Após incubação por 24 horas, pequenas colônias podem ser observadas com características de satelitismo à semeadura de $\boldsymbol{S}$. aureus. O ágar chocolate também pode ser aplicado no isolamento bacteriano, entretanto este meio apresenta menor poder de diferenciação (TAYLOR, 1999). A caracterização fenotípica de App é normalmente baseada na produção de hemólise, testes de CAMP, dependência de NAD, degradação da uréia e fermentação de açúcares, como manitol e ribose. Também são consideradas a incapacidade em fermentar arabionose, rafinose e sorbitol (PIFFER et al., 1997). Porém, variações nestas características são descritas (PIFFER et al., 1997). O teste de CAMP é uma importante ferramenta para taxonomia e identificação do App. A reação de CAMP é variável entre os sorotipos, não sendo observada em todos os isolados dos sorotipos 3 e 7 . Amostras dos sorotipos 1, 5 e 9 são geralmente hemolíticas e CAMP positivas (GUTIERREZ et al., 1993; PIFFER et al., 1997).

Através da sorotipificação podem ser obtidos dados relativos à virulência dos isolados presentes no rebanho. A sorotipificação de App pode ser realizada diretamente, pelas técnicas de aglutinação em látex, hemaglutinação indireta e testes de difusão em gel, ou de forma empírica através da análise do perfil de toxinas Apx presentes nos isolados (FREY, 1995; BLACKALL et al., 2002). Entretanto, muitos problemas são observados, como reações cruzadas, presença de 
amostras auto-aglutinantes e, principalmente, ocorrência de amostras não-sorotipifícáveis (INZANA \& MATHISON, 1987). Em muitos casos, em que a sorotipificação não é possível, o perfil de toxinas Apx pode ser utilizado para correlação com um provável sorotipo. Entretanto, a classificação de isolados de App nos diferentes sorotipos, baseada unicamente na presença das toxinas Apx, pode induzir a muitos erros de classificação (BECK et al., 1994). Problemas nos esquemas de sorotipificação vêm sendo descritos e podem refletir o surgimento de novos sorotipos desta bactéria, como o sorotipo 15, descrito na Austrália (BLACKALL et al., 2002).

Diversos ensaios imunoenzimáticos (ELISA) foram desenvolvidos para o diagnóstico da pleuropneumonia suína. Esses são baseados em antígenos extraídos com EDTA (WILLSON et al., 1988), polissacarídeos capsulares e lipopolissacarídeos de cadeia longa (GOTTSCHALK et al., 1994). KICH et al. (1999) realizaram um estudo a campo no estado de Santa Catarina, onde compararam a cultura bacteriana com os resultados obtidos por ELISA em animais oriundos de rebanhos com ou sem histórico da infecção por App. Este trabalho comprovou que o teste de ELISA é eficiente para a diferenciação entre rebanhos e indivíduos infectados por App, dos demais, mas esta metodologia não pode ser associada aos resultados obtidos na cultura da bactéria. Ocorreram ainda grandes variações nos perfis bioquímicos de amostras NAD-dependentes isoladas de animais sadios. A tabela 1 contém alguns dos resultados obtidos por KICH et al. (1999), bem como a correlação entre os dados referentes ao ELISA e ao isolamento de bactérias NADdependentes nos suínos amostrados. SCHALLER et al. (2000) afirmam que a caracterização por testes bioquímicos e sorológicos de App e de outras bactérias NAD-dependentes, isoladas de rebanhos sem PPS, pode apresentar algumas dificuldades. Estas estão associadas ao caráter subjetivo na interpretação dos resultados, ao desenvolvimento fastidioso da bactéria e ao surgimento de amostras não-sorotipificáveis. Somada a todos estes fatores, a ocorrência de bactérias que mimetizam o perfil fenotípico e antigênico de App no trato respiratório suíno, ressalta a importância do desenvolvimento de métodos moleculares, baseados na reação em cadeia da polimerase (Polymerase Chain Reaction- PCR) para permitir a obtenção de mais informações sobre a taxonomia e a epidemiologia deste patógeno.

\section{Métodos moleculares utilizados para diagnóstico e caracterização de App}

Estudo da presença de cápsula e das toxinas RTX No diagnóstico da PPS, a técnica de PCR facilita a identificação de amostras não- sorotipificáveis, bem como reduz o tempo necessário para a obtenção de resultados conclusivos em até um dia de trabalho (CHO \& CHAE, 2001). Tendo em vista a alta sensibilidade, especificidade e facilidade na execução da técnica de PCR e a presença da cápsula nos isolados de App, a amplificação do gene $c p x$ vem sendo utilizada para o seu diagnóstico (KLEIN et al., 2003). Vários testes de PCR baseados nos genes que codificam as toxinas Apx foram desenvolvidos para o diagnóstico da pleuropneumonia suína (COLLARES, 2000; GRAM et al., 2000). Entretanto, a homologia com os genes das toxinas ApxI var suis e ApxII var suis de A. suis impede a aplicação destes genes como alvo para o diagnóstico da infecção por App, sem o isolamento do agente (OSTAAIJEN et al., 1997; SCHALLER et al., 2000).

Em experimentos realizados por COLLARES (2000) e KLEIN et al. (2003), foram caracterizados 127 isolados NAD-dependentes, a partir do trato respiratório de suínos, sendo 63 isolados de quadros agudos de PPS e 64 isolados obtidos de suínos assintomáticos provenientes de rebanhos com e sem histórico de PPS. A tabela 2 resume e associa os resultados obtidos nestes dois estudos e demonstra uma concordância de $100 \%$ entre os métodos microbiológicos (hemólise, CAMP e urease), a sorotipificação e os métodos moleculares (PCR para os genes cpx e apx $I, I I$ e $I I I)$, quando aplicados para isolados de A. pleuropneumoniae de suínos doentes. Entretanto, para os isolados de suínos sadios foram observadas discrepâncias na classificação microbiológica e molecular, principalmente para aqueles não-sorotipificáveis. Destas amostras, 16 (13\%) apresentaram resultados conflitantes entre as caracterizações bioquímica, sorológica e a tipagem molecular. Os dados de COLLARES (2000) e KLEIN et al. (2003) também mostram a grande prevalência de bactérias NAD-dependente, capazes de mimetizar o perfil fenotípico de App. Estas bactérias, contudo, podem ser distinguidas facilmente por métodos moleculares. Entre elas, pode-se citar o Actinobacillus minor.

\section{Detecção do gene apxIVA e seqüenciamento do rDNA 16S}

A família Pasteurellaceae compreende organismos dos gêneros Haemophilus, Actinobacillus e Pasteurella. Estudos taxonômicos envolvendo esta família estão sendo realizados empregando métodos fenotípicos e moleculares. Contudo, diversos pesquisadores têm demonstrado a grande complexidade na classificação destas bactérias (DEWHIRST et al., 1993). Através da análise de 
Tabela 1 - Relação entre os resultados obtidos pelo isolamento bacteriano (I) e teste de ELISA (E), para rebanhos com e sem histórico de infecção por A. pleuropneumoniae.

\begin{tabular}{|c|c|c|c|c|c|c|c|}
\hline $\begin{array}{l}\text { Histórico } \\
\text { prévio de PPS }\end{array}$ & $\begin{array}{c}\text { Classificação por ELISA } \\
\text { do rebanho }\end{array}$ & amostras & $\mathrm{I}+{ }^{\mathrm{a}}$ & $\mathrm{E}+{ }^{\mathrm{b}}$ & $\mathrm{I}+\mathrm{E}+{ }^{\mathrm{c}}$ & I- E- ${ }^{d}$ & $\begin{array}{c}\% \\
\text { Concordância }\end{array}$ \\
\hline+ & + & 67 & 28 & 5 & 3 & 31 & $57 \%$ \\
\hline - & + & 40 & 13 & 7 & 5 & 25 & $75 \%$ \\
\hline - & - & 10 & 4 & 0 & 0 & 6 & $60 \%$ \\
\hline
\end{tabular}

FONTE: adaptado de KICH et al. (1999)

a:I+ = número de leitões com isolamento positivo na cultura bacteriológica;

b:E+ = número de leitões positivos somente no teste de ELISA;

c: $\mathrm{I}+\mathrm{E}+=$ número de leitões positivos nos dois testes;

d: I-E- = número de leitões negativos nos dois testes.

hibridização DNA-DNA e comparação das seqüências dos genes que codificam rRNA $16 \mathrm{~S}$, três novas espécies da família Pasteurellaceae foram propostas, como sendo pertencentes a diferentes grupos filogenéticos. O táxon Haemophilus minor foi separado em três novas espécies: Actinobacillus minor, Actinobacillus porcinus e Actinobacillus indolicus (MØLLER et al., 1996). Estas espécies diferem de App principalmente pela ausência de hemólise e pela pouca patogenicidade para os suínos (CHIERS et al., 2001; KIELSTEIN et al., 2001).

Recentemente, um novo tipo de RTX foi identificado e caracterizado em App, sendo denominada ApxIV. Foi demonstrado que esta toxina protéica é expressa somente in vivo, o que sugere sua importância na patogênese da enfermidade, (SCHALLER et al., 1999; SCHALLER et al., 2000). Todos os sorotipos de A. pleuropneumoniae possuem o gene apxIVA. Este gene não foi encontrado em nenhuma das espécies correlatas pertencentes à família Pasteurellaceae, o que comprova a sua especificidade (CHO \& CHAE, 2001). Essa propriedade foi imediatamente explorada no diagnóstico da PPS através do desenvolvimento de um PCR específico (SCHALLER et al. 2001). CHO \& CHAE (2001) comprovaram a presença do gene em todos os isolados de campo testados, indicando que esta toxina pode ser de grande importância em métodos de diagnóstico e na construção de vacinas contra a pleuropneumonia suína.

A análise da sequiência de DNA de regiões hipervariáveis do gene que codifica o rRNA 16 S tem sido de grande utilidade em estudos de taxonomia molecular, permitindo a diferenciação de espécies relacionadas (KIELSTEIN et al., 2001). Na família Pasteurellaceae, a aplicação desta técnica é muito importante para resolver erros nas classificações, especialmente quanto ao gênero bacteriano
(DEWHIRST et al., 1993). SCHALLER et al. (2001) empregaram esta metodologia para caracterizar isolados com perfil bioquímico e de toxinas semelhantes a App, contudo com resultado negativo para a amplificação do gene apxIVA. Estes autores comprovaram a existência de bactérias que mimetizam as características de App, inclusive apresentando a toxina Apx II.

Estudo visando a caracterização dos isolados brasileiros obtidos de suínos saudáveis, bioquimicamente classificados como App e com problemas quanto à classificação sorológica e molecular (Tabela 2) foi desenvolvido (COSTA, 2002). Neste estudo, foram analisadas a amplificação por PCR do gene apxIVA e a determinação da seqüência parcial do rDNA $16 \mathrm{~S}$. Os resultados demonstraram que nenhum dos isolados previamente classificados como App, pertenciam a esta espécie, sendo classificadas com base no sequenciamento do rDNA 16S nos grupos de bactérias NAD-dependentes pertencentes a família Pasteurellaceae (tabela 2).

\section{Determinação de sorotipos em isolados de App pela técnica de RAPD}

A técnica de RAPD (Randon Amplified Polymorfic DNA) baseia-se na amplificação de fragmentos específicos do DNA genômico, utilizando apenas um pequeno iniciador com seqüência arbitrária de nucleotídeos (WILLIANS et al., 1990; WELSH \& McClELLAND, 1990). Como discutido anteriormente, a ocorrência de amostras nãosorotipificáveis é descrita em App, principalmente em amostras originárias de rebanhos sem histórico de pleuropneumonia suína. Os testes de sorotipificação convencionais, embora sejam eficientes, podem apresentar alguns problemas quanto à presença de amostras sem um perfil sorológico compatível com os previamente descritos (MOLNÁR \& MOLNÁR, 
Tabela 2 - Características bioquímicas, sorológicas e moleculares dos isolados de A. pleuropneumoniae e espécies relacionadas submetidos ao PCR para os genes cpx e apxIA, IIA, IIIA e IVA e seqüenciamento do rDNA16S.

\begin{tabular}{|c|c|c|c|c|c|c|c|c|c|c|c|c|}
\hline Amostra & 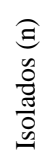 & 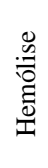 & 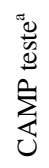 & 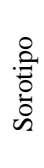 & 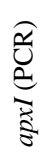 & 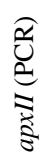 & 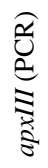 & 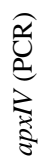 & $\begin{array}{c}16 \mathrm{~S} \\
(\mathrm{PCR})\end{array}$ & 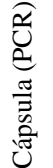 & Classificação bioquímica & $\begin{array}{c}\text { Classificação por } \\
\text { seqüenciamento de rRNA16S }\end{array}$ \\
\hline
\end{tabular}

\begin{tabular}{|c|c|c|c|c|c|c|c|c|c|c|c|c|}
\hline \multicolumn{13}{|l|}{ Casos clínicos } \\
\hline & 17 & + & $\mathrm{H}^{\mathrm{b}}$ & 3 & - & + & + & + & $\mathrm{NR}^{\mathrm{c}}$ & + & App & NR \\
\hline & 26 & + & $\mathrm{H}$ & 5 & + & + & - & + & NR & + & App & NR \\
\hline & 5 & + & $\mathrm{H}$ & 7 & + & + & - & + & NR & + & App & NR \\
\hline & 1 & + & $\mathrm{H}$ & 11 & - & + & - & + & NR & + & App & NR \\
\hline & 8 & + & $\mathrm{H}$ & $\mathrm{NS}^{\mathrm{d}}$ & - & + & + & + & NR & + & App & NR \\
\hline & 3 & + & $\mathrm{H}$ & NS & + & + & - & + & NR & + & App & NR \\
\hline & 3 & + & $\mathrm{H}$ & NS & + & - & + & + & NR & + & App & NR \\
\hline \multicolumn{13}{|l|}{ Rebanhos } \\
\hline & 3 & + & + & 7 & - & + & - & + & NR & + & App & NR \\
\hline & 1 & + & + & 12 & - & + & - & + & NR & + & App & NR \\
\hline & 6 & + & - & NS & - & - & - & - & + & - & App & A.minor \\
\hline & 3 & + & - & NS & - & - & - & - & + & - & App & A.porcinus \\
\hline & 1 & + & - & NS & - & - & - & - & + & - & App & Pasteurella sp. \\
\hline & 1 & + & - & NS & - & + & + & - & + & - & App & A.minor \\
\hline & 1 & + & - & NS & - & + & + & - & + & - & App & A. indolicus \\
\hline & 1 & + & - & NS & - & + & - & - & + & - & App & A. minor \\
\hline & 1 & + & - & NS & - & + & - & - & + & - & App & Pasteurella sp. \\
\hline & 1 & + & - & NS & + & + & - & - & + & - & App & A. minor \\
\hline
\end{tabular}

FONTE: COLLARES (2000); KLEIN (2000); COSTA (2002).

${ }^{a}$ CAMP: Efeito hemolítico sinérgico das toxinas de A.pleuropneumoniae e $S$. aureus em eritrócitos de ovinos;

${ }^{\mathrm{b}} \mathrm{H}$ : isolados Hemolíticos;

${ }^{\mathrm{N}} \mathrm{NR}$ : teste não realizado;

${ }^{\mathrm{d}} \mathrm{NS}$ : amostra não-sorotipificável.

1994). A amplificação por RAPD pode ser utilizada para a classificação de isolados de App dentro dos sorotipos descritos (HENNESSY et al., 1993). Entretanto, mesmo com o seu grande poder de discriminação essa técnica pode ser ineficaz para separar isolados pertencentes a sorotipos relacionados, como os sorotipos 1 e 5. Por outro lado, essa técnica pode ser utilizada para estudos epidemiológicos visando à distribuição de uma determinada amostra dentro de uma área. Entretanto, a presença de plasmídeos e a variabilidade genética dos isolados podem também interferir nos resultados (HENNESSY et al., 1993).

VAZ (2002) aplicou a técnica de RAPD em diferentes isolados de App sorotipificáveis e nãosorotipificáveis, obtidos de suínos com e sem pleuropneumonia. Neste estudo, além da correlação dos resultados obtidos por RAPD com aqueles da sorotipificação convencional, foi possível genotipar 14 isolados sem sorotipificação prévia, dentro dos padrões obtidos para as amostras de referência de App.
Segundo o autor, apesar dos sorotipos 3 e 5 não terem sido diferenciados pelo RAPD, esta técnica pode ser considerada como uma alternativa para a caracterização de amostras cuja sorotipificação convencional não é possível. Ainda neste estudo, a diferenciação entre os isolados dos sorotipos 3 e 5 foi possível através da análise do perfil dos genes que codificam as toxinas Apx I e III, realizada através de PCR.

\section{CONCLUSÕES}

O diagnóstico, a sorotipificação e a caracterização de isolados de App são ferramentas muito importantes para a implementação de programas de controle e de profilaxia para a pleuropneumonia suína. Neste sentido, as técnicas moleculares são de grande valia, quando utilizadas em associação com a microbiologia clássica, principalmente para resolver possíveis dúvidas e reduzir o tempo necessário à obtenção de resultados conclusivos. Problemas na 
classificação microbiológica convencional podem ocorrer, em sua maioria, em amostras isoladas do trato respiratório de suínos saudáveis, nos quais se observa uma flora microbiana com perfil fenotípico semelhante ao encontrado em App. Baseados em diversos estudos visando à classificação e a caracterização de isolados de App e espécies relacionadas, podemos concluir que a amplificação do gene apxIVA apresenta uma grande utilidade na identificação e confirmação do agente. Entretanto, a associação desta técnica à cultura e sorotipificação, bem como aos demais métodos moleculares, como PCR para os genes $c p x$ e $a p x$, seqüenciamento do rDNA $16 \mathrm{~S}$ e RAPD, podem melhorar a caracterização deste microrganismo. Estes dados relativos ao sorotipo envolvido e a sua correlação com a patogenicidade para os suínos permitiriam a adoção de medidas eficazes para controle da enfermidade, reduzindo, desta forma os prejuízos associados à PPS.

\section{PERSPECTIVAS}

Esforços são necessários para melhor entender a patogenicidade bacteriana e desenvolver metodologias para o diagnóstico rápido e preciso da enfermidade. Novos estudos deverão se concentrar na padronização da técnica de PCR para a amplificação direta do DNA bacteriano nas amostras de suabes nasais, tecido pulmonar ou de amígdalas. Segundo SCHALLER et al. (2001), as diferentes metodologias desenvolvidas para identificar e detectar App, baseadas na amplificação do gene apxIVA, e em testes de ELISA para detecção de anticorpos contra esta toxina, possibilitariam maior rapidez e praticidade no diagnóstico da infecção por App nos suínos (SCHALLER et al., 1999; CHO \& CHAE, 2001).

Alguns sorotipos de App, em especial o sorotipo 3 é considerado como de pouca virulência, e nenhuma importância epidemiológica em alguns países. Contudo, no Brasil, este apresenta grande relevância (PIFFER et al., 1987; PIFFER et al., 1997). Devido às diferenças em termos da patogenicidade dos isolados do sorotipo 3 brasileiros em relação ao descrito em outros locais, torna-se necessário o maior entendimento de diferenças que possam ocorrer no genoma destes isolados. A técnica de RDA (Representational Differences Analysis) vem sendo amplamente utilizada para comparar genomas altamente relacionados empregando a hibridização subtrativa. Por esta metodologia, os fragmentos de DNA presentes especificamente em um dos genomas podem ser isolados e caracterizados (CLAUS et al., 2000). Esta metodologia vem sendo utilizada com sucesso para caracterização de muitos patógenos bacterianos, como Escherichia coli e Vibrio cholerae (TINSLEY \& NASSIF, 1998; CLAUS et al., 2000). Portanto, a técnica de RDA poderia ser aplicada na determinação de diferenças existentes entre isolados do sorotipo 3 obtidos no Brasil com os de outros países, respondendo algumas dúvidas a respeito dos mecanismos de patogenicidade desta bactéria para os suínos.

\section{REFERÊNCIAS BIBLIOGRÁFICAS}

BLACKALL, P.J. et al. Proposal of a new serovar of $\boldsymbol{A}$. pleuropneumoniae: serovar 15. Veterinary Microbiology, v.84, p.47-52, 2002.

BECK, M. et al. RTX toxin genotypes and phenotypes in $\boldsymbol{A}$. pleuropneumoniae field strains. Journal of Clinical Microbiology, v.32, n.11, p.2749-2754, 1994.

BURROWS, L.L.; LO, R.Y. Molecular characterization of an RTX toxin determinant from Actinobacillus suis. Infection and Immunity, v.60, n.6, p.2166-2173, 1992.

CHIERS, K. et al. Pathogenicity of A. minor, A. indolicus and A. porcinus strains for gnotobiotic piglets. Journal of Veterinary Medicine B, v.48, p.127-131, 2001.

CHIERS, K. et al. A. pleuropneumoniae infections in closed swine herds: infection patterns and serological profiles. Veterinary Microbiology, v.85, p.343-352, 2002.

CHRISTENSEN, G. et al. Diseases of the respiratory system. In: STRAW, S.E. et al. Diseases of swine. 8.ed. Ames : Iowa State University 1999. p.913-940.

CHO, W.S.; CHAE, C. Genotypic prevalence of apxIV in $\boldsymbol{A}$. pleuropneumoniae field isolates. Journal of Veterinary Diagnostic Investigation, v.13, p.175-177, 2001.

CLAUS, H. et al. Differential distribution of novel restriction systems in clonal lineages of Neisseria meningitidis. Journal of Bacteriology, v.182, p.1296-1303, 2000

COLLARES, R.M. Análise molecular dos genes para as toxinas de A. pleuropneumoniae em isolados de campo. 2000. $85 \mathrm{f}$. Dissertação (Mestrado em Ciências Veterinárias) - Curso de Pósgraduação em Ciências Veterinárias, Universidade Federal do Rio Grande do Sul.

COSTA, M.M. Actinobacillus pleuropneumoniae e espécies relacionadas: genes apxIVA e rDNA 16S. 2002. $79 \mathrm{f}$. Dissertação (Mestrado em Biologia Molecular e Celular) - Curso de Pós-graduação em Biologia Celular e Molecular. Universidade Federal do Rio Grande do Sul.

DEWHIRST F.E. et al. Phylogeny of the Pasteurellaceae as determined by comparison of $16 \mathrm{~S}$ ribosomal ribonucleic acid sequences. Zenthalblat Bakterology, v.279, p.35-44, 1993.

DOM, P. et al. NAD independent A. pleuropneumoniae strains: Production of RTX toxins interactions with porcine phagocytes. Veterinary Microbiology, v.39, p.205-218, 1994. 
DOM, P.; HAESEBROUCK, F. Comparative virulence of NADdependent and NAD-independent A. pleuropneumoniae strains. Journal of Veterinary Medicine B, v.39, p.303-306, 1992.

FODOR, L. et al. Biochemical and serological properties of $\boldsymbol{A}$. pleuropneumoniae biotype 2 strains isolated from swine. Veterinary Microbiology, v.20, p.173-180, 1989.

FREY, J.; KUHN, R.; NICOLET, J. Association of the CAMP phenomenon in Actinobacillus pleuropneumoniae with the RTX toxins ApxI, ApxII and ApxIII. FEMS Microbiology Letters, v.124, p.245-252, 1994.

FREY, J. Virulence in A. pleuropneumoniae and RTX toxins. Trends in Microbiology, v.3, n.7, p.257-261, 1995.

GOTTSCHALK, M. et al. Evaluation of Long-chain Lipopolysaccharides (LC-LPS) of A. pleuropneumoniae Serotype 5 for the serodiagnosis of swine pleuroneumonia. Veterinary Microbiology, v.38, p.315-327, 1994.

GRAM, T.; AHRENS, P.; NIELSEN, J.P. Evaluation of a PCR for detection of A. pleuropneumoniae in mixed bacterial culture from tonsils. Veterinary Microbiology, v.51, p.95-104, 1996.

GRAM, T. et al. An A. pleuropneumoniae PCR typing system based on the apx and omla genes-evaluation of isolates from lungs and tonsils of pigs. Veterinary Microbiology, v.75, p.43-57, 2000 .

GUTIERREZ, C.B. et al. Characterization of V Factor-dependent organisms of the family Pasteurellaceae isolated from porcine pneumonic lungs in Spain. Comparative Immunology Microbiology Infection, v.6, p.123-130, 1993.

HAESEBROUCK, F. et al. A. pleuropneumoniae infections in pigs: the role of virulence factors in pathogenesis and protection. Veterinary Microbiology, v.58, p.239-249, 1997.

HENNESSY, K.J.; IANDOLO, J.J.; FENWICK, B.W. Serotype identification of Actinobacillus pleuropneumoniae by arbitrarily primed polymerase chain reaction. Journal of Clinical Microbiology, v.31, p.1155-1159, 1993.

INZANA, T.J.; MATHISON, B. Serotype specific and immunogeicity of the capsular polymer of Haemophilus pleuropneumoniae serotype 5. Infection and Immunity, v.55, n.7, p.1580-1587, 1987.

INZANA, T.J. et al. Safety, stability and efficacy of noncapsulated mutants of Actinobacillus pleuropneumoniae for use in live vaccines. Infection and Immunity, v.61, p.191-197, 1993.

JANSEN, R. et al. Cloning and characterization of the $\boldsymbol{A}$. pleuropneumoniae-RTX-toxin III (Apx III) gene. Infection and Immunity, v.61, n.5, p.947-954, 1993.

JANSEN, R. et al. Knockout mutants of A. pleuropneumoniae serotype 1 that are devoid of RTX toxins do not activate or kill porcine neutrophils. Infection and Immunity, v.63, n.1, p.2737, 1995.

JOBERT, J.L. et al. Experimental transmission of $\boldsymbol{A}$. pleuropneumoniae to pigs. Canadian Journal of Veterinary Research, v.64, n.1, p.21-26, 2000.

$\mathrm{KICH}$, J.D. et al. Utilização de um teste de ELISA polivalente para a detecção de anticorpos contra A. pleuropneumoniae.
Arquivo Brasileiro de Medicina Veterinária e Zootecnia, v.51, n.5, p.409-414, 1999.

KIELSTEIN, P. et al. Phenotypic and genetic characterization of NAD-Dependent Pasteurellaceae from respiratory tract of pigs and their possible pathogenic importance. Veterinary Microbiology, v.81, p.243-255, 2001.

KLEIN, C.S. et al. Detection of A. pleuropneumoniae in filed strains form healthy and diseased pigs. Current Microbiology, v.46, n.6, p.443-447, 2003.

LOCATELLI, J.C. et al. Ocorrência da pleuropneumonia suína causada pelo Haemophilus pleuropneumoniae. In: CONGRESSO ESTADUAL DE MEDICINA VETERINÁRIA, 6 ., 1981, Gramado. Anais... Gramado : Sociedade Veterinária do Rio Grande do Sul e Associação de Clínicos veterinários de Pequenos Animais, 1981. p.36-37.

MØLLER, K. et al. Actinobacillus minor sp. nov.; Actinobacillus porcinus sp. nov., and Actinobacillus indolicus sp. nov., three new $\mathrm{V}$ factor-dependent species from the respiratory tract of pigs. International Journal of Systematic Bacteriology, v.46, n.4, p.951-956, 1996.

MOLNÁR, E.; MOLNÁR, L. The value of different serological test in serotyping of A. pleuropneumoniae strains. Acta Microbiologica et Immunologica Hungarica, v.41, n.3, p.247253, 1994.

OSTAAIJEN, J.V. et al. Actinobacillus suis strains isolated from healthy and diseased swine are clonal and carry apxICABDvarsuis and apxIICAvar. suis toxin genes. Journal of Clinical Microbiology, v.35, n.5, p.1131-1137, 1997.

PIFFER, I.A. et al. Sorotipos de Haemophilus (Actinobacillus) pleuropneumoniae isolados de suínos no Brasil. Pesquisa Veterinária Brasileira, v.3, n.7, p.79$83,1987$.

PIFFER, I.A.; BRITTO, J.R.F. Pneumonia em suínos. Suinocultura Dinâmica, v.2, n.8, p.1-6, 1993.

PIFFER, I.A. et al. Caracterização bioquímica e sorológica de amostras de A. pleuropneumoniae isoladas no Brasil. Arquivo Brasileiro de Medicina Veterinária e Zootecnia, v.49, n.1, p.123-129, 1997.

RIOUX, S. et al. Isolation and characterization of a capsule deficient mutant of Actinobacillus pleuropneumoniae serotype 1. Microbial Pathogenesis, v.28, p.279-289, 2000.

ROHRBACH, B.W.; HALL, R.F.; HITCHCOCK, J.P. Effect of subclinical infection with $A$. pleuropneumoniae in commingled feeder swine. Journal of American Veterinary Medical Association, v.202, n.7, p.1095-1098, 1993.

SAVOYE, C. et al. A PCR used to study aerosol transmission of $\boldsymbol{A}$. pleuropneumoniae from samples of live pigs under experimental conditions. Veterinary Microbiology, v.73, p.337-347, 2000.

SCHALLER, A. et al. Characterization of apxIVA, a new RTX determinant of A. pleuropneumoniae. Microbiology, v.145, p.2015-2116, 1999.

SCHALLER, A. et al. Apx toxins in Pasteurellaceae species from animals. Veterinary Microbiology, v.74, p.47-62, 2000. 
SCHALLER, A. et al. Identification and detection of $\boldsymbol{A}$. pleuropneumoniae by PCR based on the gene apxIVA. Veterinary Microbiology, v.79, p.47-62, 2001.

SOBESTIANSKY, J.; PIFFER, I.A.; FREITAS, A.R. Impacto das doenças respiratórias de suínos nos sistemas de produção do estado de Santa Catarina. Comunicado Técnico, n.123, p. 1-4, 1987.

STRAW, B.E.; TUOVINEM, V.K.; BIGRAS-POULIN, M. Estimation of the cost of pneumonia in swine herds. Journal of American Veterinary Medical Association, v.195, n.12, p.1702-1706, 1989.

TASCÓN, R.I. et al. The RTX haemolysins ApxI and ApxII are majors virulence factors of the swine pathogen $\boldsymbol{A}$. pleuropneumoniae: evidence from mutational analysis. Molecular Microbiology, v.14, n.2, p.207-212, 1994

TAYLOR, D.J. A. pleuropneumoniae. In: STRAW, S.E. et al. Diseases of swine. 8.ed. Ames : Iowa State University, 1999. p.913-940.

TINSLEY, C.R.; NASSIF, X. Analysis of the genetic differences between Neisseria meningitidis and Neisseria gonorrhoeae: two closely related bacteria expressing two different pathogenicities. Proceedings of National Academy of Sciences, v.93, p.1109-1114, 1998.

VAZ, C.S.L. Genotipificação de amostras sorotificáveis e não sorotipificáveis de A. pleuropneumoniae através de RAPD. 2002. 85f. Dissertação (Mestrado em Ciências Veterinárias) - Curso de Pós-graduação em Ciências Veterinárias, Universidade Federal do Rio Grande do Sul.

WELSH, J.; MCLLELLAND, M. Fingerprinting genomes using PCR with arbitrary primers. Nucleic Acids Research, v.18, n.22, p.6531-6535, 1990

WILLSON, P.J.; SCHIPPER, C.; MORGAN D. The use of an enzime-linked immunoabsorbent assay for diagnosis of $\boldsymbol{A}$. pleuropneumoniae infection in pigs. Canadian Veterinary Journal, v.29, p.583-584, 1988.

WILLIAMS, J.G.K. et al. DNA polymorphisms amplified by arbitrary primers are useful as genetic markers. Nucleic Acids Research, v.18, n.22, p.6531-6535, 1990. 